\title{
Synthesis and characterization of catalytic metal semiconductor-doped siliceous materials with ordered structure for chemical sensoring
}

\author{
Elena Mihaela Seftel, Pegie Cool, Anita Lloyd Spetz and Lutic Doina
}

\section{Linköping University Post Print}

\section{Tweet}

N.B.: When citing this work, cite the original article.

The original publication is available at www.springerlink.com:

Elena Mihaela Seftel, Pegie Cool, Anita Lloyd Spetz and Lutic Doina, Synthesis and characterization of catalytic metal semiconductor-doped siliceous materials with ordered structure for chemical sensoring, 2013, Journal of porous materials, (20), 5, 1119-1128. http://dx.doi.org/10.1007/s10934-013-9694-2

Copyright: Springer Verlag (Germany) http://www.springerlink.com/?MUD=MP 


\title{
Synthesis and characterization of catalytic metal semiconductor-doped siliceous materials with ordered structure for chemical sensoring
}

\author{
Elena Mihaela Seftel ${ }^{a, b}$, , Pegie Cool ${ }^{b}$, Anita Lloyd-Spetz ${ }^{c}$ and Doina Lutic ${ }^{a^{*}}$ \\ ${ }^{a}$ Department of Materials Chemistry, Al. I. Cuza University of lasi, Bvd. Carol I, No. 11, \\ 700506, Romania \\ ${ }^{b}$ Laboratory of Adsorption and Catalysis, Department of Chemistry, University of \\ Antwerpen (CDE), Universiteitsplein 1, 2610 Wilrijk, Antwerpen, Belgium \\ 'Division of Applied Sensor Science, Department of Physics, Chemistry and Biology, \\ Linköping University, SE-581 83 Linköping, Sweden
}

*Corresponding author: Doina Lutic

Tel. +40740236565

Fax: +40 232201313

E-mail:doilub@yahoo.com

\begin{abstract}
Sensing materials based on doped mesoporous silica of SBA-15 type were obtained by repeated wet impregnation of the solid with semiconductive oxides ( $\mathrm{Sn}$ and $\mathrm{In}$ ) and noble metal (Pt). The mesoporous structure of SBA was preserved during the doping and calcination of the solid, although slight pore size narrowing occurred as shown by the BET adsorption analysis. The solid was deposited by the casting technique as a thin layer on a finger structure. The modifications of its electrical resistance values in the presence of hydrogen and propene (50-400 ppm), at temperature values of $450^{\circ} \mathrm{C}$ was used as sensing parameter, in the presence of propene and hydrogen. The sensitivity to propene was higher than that to hydrogen.
\end{abstract}

Keywords

SBA-15 doping, indium oxide, tin oxide, platinum, propene and hydrogen sensing 


\section{Introduction}

Semiconducting oxides-based gas sensors have attracted much attention due to their applications in environmental monitoring, personal safety or national security [1]. High gas responses for detecting trace concentration of gases can be accomplished by employing welldefined nanostructures [2]. Up to now, extensive foundational and technological efforts have been dedicated to manufacture high performance gas sensors based on various semiconducting metal oxides $[3,4]$. The sensing device must offer sensitivity and selectivity to the detected species, high speed of response and stability in time upon use. Research interests to prepare size- and shapecontrolled nanoparticles continued in the past few years due to their diverse morphologies, interesting properties and important potential applications in nanodevices [5].

Materials with pores in the nanometer range, $i$. $e$. nanoporous materials, are of great interest for potential application as selective sorbents, solid catalysts, drug delivery systems, sensors or hosts for nanoscale objects (nanoparticles, nanowires, biomolecules, etc.) [6].

Among the most used semiconductor oxides, $\mathrm{SnO}_{2}, \mathrm{ZnO}, \mathrm{TiO}_{2}, \mathrm{In}_{2} \mathrm{O}_{3}$ and $\mathrm{Fe}_{2} \mathrm{O}_{3}$ are widely cited as suitable species for chemical sensing of nitrogen oxides, ammonia, carbon monoxide and hydrocarbons [7-10]. Selective gas detection using oxide semiconductor sensors is often difficult because a number of different reducing gases can interact electrochemically with negatively charged surface oxygen. Various approaches have been employed to enhance the selectivity of sensors, which include the addition of noble metal and oxide catalysts [11,12].

The chemical reactions occurring on pure and noble metal-containing semiconductor oxides between several species in the sensor area result in changes of the layer mass, surface potential change, electrical resistance, optical changes, etc. There are many parameters involved in the use of solid materials for gas sensor applications, like adsorption ability, catalytic activity, sensitivity (density of active surface states), thermodynamic stability, etc. Sensors based on the two components mixed together are maybe more sensitive than the individual components alone, suggesting a synergistic effect between the two components. When the catalytic action of the two components complements each other, the performance of the gas sensors will be enhanced. In addition to the synergistic effect, the hetero-junction interface between two or more components also contributes to the enhancement of the composite gas sensor performance [13-15].

The formation of hetero-junction barriers in ambient air and their disruption on exposure to the target gas may be the employer principle. Therefore, the resistance and the proportion of the hetero-junctions in the composite sensor becomes a control factor to the gas sensor performance. Moreover, the changing in the proportion of each material present in the composite yields a wide range of sensors materials with very different sensing characteristics [2].

Many oxide materials appear favorable in some of these properties, but very few are suitable for all the requirements. Therefore, recent research is now turning its attention on composite materials, such as $\mathrm{SnO}_{2}-\mathrm{TiO}_{2}$ [16], $\mathrm{SnO}_{2}-\mathrm{In}_{2} \mathrm{O}_{3}$ [17], $\mathrm{ZnO}-\mathrm{SnO}_{2}$ [18] etc.

Among the numerous kinds of methods (dry or wet, for bulk materials or for thin layers) available to prepare such materials, a remarkably interesting one is the templated synthesis, where the desired product is encapsulated into the channels and pores of a host [19, 20]. A big part of the 
current research on mesoporous materials focuses on the development of methods for the generation of functional porous solids with tailored porosity and network structure, and specifically positioned functionalities.

Special attention was particularly paid to obtaining mesoporous materials with tunable pore size ranging from 2 to $30 \mathrm{~nm}$ and their use as hosts for transition metal oxidic nanoparticles. The synthesis of nanosized materials within mesopores occurs via a constricted growth process, which provides the control of their size, allowing tuning their dimensions to certain values. The discovery of mesoporous silicas, such as M41s and SBA-15, has stimulated intensive studies of "host-guest” chemistry inside their channels, resulting in materials with remarkable applications in catalysis, selective adsorbents, sensors and nanomaterials fabrication [21, 22].

These classes of ordered mesoporous materials are generated through cooperative selfassembly of amphiphilic structure-directing agents and inorganic precursors.

Mesoporous SBA-15 silica has become a promising oxide support for many catalysts, due to its high specific surface area $\left(600-1000 \mathrm{~m}^{2} / \mathrm{g}\right)$ and to the silanol concentration, allowing the immobilization of various kinds of species on active sites with high dispersion. It has a hexagonal array of uniform tubular channels with pore diameters in the range of $5-30 \mathrm{~nm}$, much larger than those of MCM-41, involving much lower internal diffusion resistance. Moreover, the thick pore wall (3.1-6.4 nm) provides high thermal stability and hydrothermal stability [23-25]. This mesoporous material with uniform pore size and periodic porous structural properties is a suitable candidate for the confined immobilization and growth of semiconductive oxides nanostructures [26, 27].

Nowadays there is a trend for the miniaturization of the sensing devices for several gas species used as combustibles especially in the household applications, able to replace the bulky and energy consuming Figaro thick layer devices, while keeping a high sensitivity and selectivity of the response of the sensing layer to the detected species. The role of these devices is to detect the leakages of combustible gas and be able to start an alert as efficient as possible. Since usually the audible alert is governed by a gas valve automatic shutdown which needs a manual reset to reopen, it is important to assure on one hand efficient leakage detection and to avoid, on another hand, avoid false energy, time and cost consuming alerts. This target can be achieved by the use of efficient gas sensing layers, included in a miniaturized device [28].

The detection is based on the electrical resistance change of the sensing surface when an oxidation reaction occurs on it. The oxygen is adsorbed as anions $\mathrm{O}^{\mathrm{n}-}(\mathrm{n}=0.5 ; 1$ or 2$)$ on the surface of the sensing layer, abstracting electrons from the layer and the conductivity decreases; this resistance value is the baseline. When reducing species (hydrogen, hydrocarbons, ammonia) from the gas phase on the sensing area flow on the sensing layer, an oxidation reaction occur with the participation of the reducing molecules either from adsorbed or free state, which donate electrons, leading to the increase of its electrical resistance value [29]. There is a correspondence between the concentrations of the reducing species and the resistance modification.

In this study we employed SBA-15 as a host matrix to confine gas sensitive nanoparticles such as $\mathrm{SnO}_{2}$ and $\mathrm{SnO}_{2} / \mathrm{In}_{2} \mathrm{O}_{3}$ of nanometer size. Furthermore, the obtained nanoporous composites were doped with platinum, in order to increase the gas sensing properties [2]. The 
sensing properties of the obtained materials were tested in synthetic air containing 50-400 ppm hydrogen and propene, using a resistive-based miniaturized device.

\section{Experimental part}

\section{1. Synthesis of the mesoporous $S B A-15$ silica}

Mesoporous siliceous SBA-15 was prepared according to a well-established procedure delineated by Stucky et al. [30] using tetraethylorthosilicate (TEOS) as silica source and triblock co-polymer P-123, poly ( ethylene glycol ) - block - poly ( propylene glycol ) - block - poly ( ethylene glycol ) $\mathrm{EO}_{20} \mathrm{PO}_{70} \mathrm{EO}_{20}$ (average molar weight $=5800$, Aldrich) as a template agent under acidic conditions. The synthesis mixture had the following molar composition: 1 TEOS : $5.87 \mathrm{HCl}: 194 \mathrm{H}_{2} \mathrm{O}: 0.017 \mathrm{P} 123$. In a typical synthesis, $4 \mathrm{~g}$ of P123 was dissolved in $150 \mathrm{ml} 2 \mathrm{M}$ $\mathrm{HCl}$ aqueous solution for several hours. Subsequently, $9.14 \mathrm{ml}$ of TEOS solution was added to the homogeneous solution under vigorous stirring for $8 \mathrm{~h}$ at $45^{\circ} \mathrm{C}$. Afterwards, the suspension was aged statically for $15 \mathrm{~h}$ at $80^{\circ} \mathrm{C}$. The solid phase was recovered by filtration, washed with deionized water and dried in air at room temperature. The product was calcined in air at $550^{\circ} \mathrm{C}$ for $6 \mathrm{~h}$ $\left(1^{\circ} \mathrm{C} / \mathrm{min}\right)$ to remove the residual organic template.

\section{2. Tin oxide and tin oxide/ indium oxide doping of SBA-15}

The $\mathrm{SnO}_{2}$ and $\mathrm{SnO}_{2} / \mathrm{In}_{2} \mathrm{O}_{3}$ nanoparticles were deposited onto the mesoporous SBA-15 silica using the wet impregnation method. For the $\mathrm{SnO}_{2} / \mathrm{In}_{2} \mathrm{O}_{3}$ samples, ratios of $1 / 1$ and $3 / 1$ between $\mathrm{Sn}^{4+}$ and $\mathrm{In}^{3+}$ were used. This ratios were chosen in order to obtain ITO type structures as mentioned by Zhang et al. [31]. $35 \mathrm{~mL}$ of aqueous solutions containing, respectively, 0.004 moles of $\mathrm{SnCl}_{4},\left(0.002\right.$ moles of $\mathrm{SnCl}_{4}+0.002$ moles of $\left.\mathrm{In}\left(\mathrm{NO}_{3}\right)_{3}\right)$ and $\left(0.003\right.$ moles of $\mathrm{SnCl}_{4}+0.001$ moles of $\left.\mathrm{In}\left(\mathrm{NO}_{3}\right)_{3}\right)$, were magnetically stirred with $1 \mathrm{~g}$ SBA-15 powder for $24 \mathrm{~h}$, then the excess solution was filtered. The samples were labeled as SBA-15_SnO 2 , SBA-15_ $\mathrm{SnO}_{2} / \mathrm{In}_{2} \mathrm{O}_{3}(1 / 1)$ and SBA-15_SnO ${ }_{2} / \mathrm{In}_{2} \mathrm{O}_{3}(3 / 1)$, respectively. The solids were dried at $80^{\circ} \mathrm{C}$, and calcined at $400^{\circ} \mathrm{C}$.

2. 3. Platinum-doped $S B A-15 \_S n O_{2} / \mathrm{In}_{2} \mathrm{O}_{3}$ samples were prepared from the fore-mentioned SBA-15_SnO ${ }_{2}$, SBA-15_SnO $2 / \mathrm{In}_{2} \mathrm{O}_{3}(1 / 1)$ and $\mathrm{SBA}-15 \_\mathrm{SnO}_{2} / \mathrm{In}_{2} \mathrm{O}_{3}$ (3/1) samples. An amount of $0.4 \mathrm{~g}$ of solid powder was dispersed in $10 \mathrm{~mL}$ solution containing 0.18 mmoles of indium nitrate and 0.06 mmoles $\mathrm{H}_{2} \mathrm{PtCl}_{4}$, stirred on a lukewarm $\left(45^{\circ} \mathrm{C}\right)$ plate until the water evaporation, followed by drying at $80^{\circ} \mathrm{C}$ in an oven and finally calcined at $400^{\circ} \mathrm{C}$. A theoretic ratio of $3 / 2$ between the indium oxide and Pt corresponds to the mixture used for the impregnation. The samples were labeled as $\mathrm{SBA}-15 \_\mathrm{SnO}_{2} / \mathrm{In}_{2} \mathrm{O}_{3} / \mathrm{Pt}, \mathrm{SBA}-15 \_\mathrm{SnO}_{2} / \mathrm{In}_{2} \mathrm{O}_{3}$ (1/1)_In $\mathrm{I}_{2} \mathrm{O}_{3} / \mathrm{Pt}$ and SBA-15_SnO ${ }_{2} / \mathrm{In}_{2} \mathrm{O}_{3}(3 / 1) \_\mathrm{In}_{2} \mathrm{O}_{3} / \mathrm{Pt}$, respectively. The synthesis procedures are listed together in Table 1. 
Table 1. The synthesis procedures for the obtained samples

\begin{tabular}{|c|c|}
\hline Sample code & Preparation procedure \\
\hline SBA-15_SnO ${ }_{2}$ & Excess impregnation of SBA-15 with aqueous $\mathrm{SnCl}_{4}$ \\
\hline SBA-15_SnO ${ }_{2} / \mathrm{In}_{2} \mathrm{O}_{3}(1 / 1)$ & $\begin{array}{l}\text { Excess impregnation of } \mathrm{SBA}-15 \text { with aqueous } \\
\left(\mathrm{SnCl}_{4}+\mathrm{In}\left(\mathrm{NO}_{3}\right)_{3}\right) \text { solution mixture, } 1 / 1 \mathrm{Sn}^{4+} / \mathrm{In}^{3+} \text { molar ratio }\end{array}$ \\
\hline SBA-15_SnO ${ }_{2} / \mathrm{In}_{2} \mathrm{O}_{3}(3 / 1)$ & $\begin{array}{l}\text { Excess impregnation of } \mathrm{SBA}-15 \text { with aqueous } \\
\left(\mathrm{SnCl}_{4}+\mathrm{In}\left(\mathrm{NO}_{3}\right)_{3}\right) \text { solution mixture, } 3 / 1 \mathrm{Sn}^{4+} / \mathrm{In}^{3+} \text { molar ratio }\end{array}$ \\
\hline SBA-15_SnO $\mathrm{Sn}_{2} / \mathrm{In}_{2} \mathrm{O}_{3} / \mathrm{Pt}$ & $\begin{array}{l}\text { Impregnation and evaporation with indium nitrate and } \\
\text { chloroplatinic acid of SBA-15_SnO }{ }_{2}\end{array}$ \\
\hline $\begin{array}{l}\mathrm{SBA}-15 \_\mathrm{SnO}_{2} / \mathrm{In}_{2} \mathrm{O}_{3} \\
(1 / 1) \_\mathrm{In}_{2} \mathrm{O}_{3} / \mathrm{Pt}\end{array}$ & $\begin{array}{l}\text { Impregnation and evaporation with indium nitrate and } \\
\text { chloroplatinic acid of SBA-15_ } \mathrm{SnO}_{2} / \mathrm{In}_{2} \mathrm{O}_{3}(1 / 1)\end{array}$ \\
\hline $\begin{array}{l}\mathrm{SBA}-15 \_\mathrm{SnO}_{2} / \mathrm{In}_{2} \mathrm{O}_{3} \\
(3 / 1) \_\mathrm{In}_{2} \mathrm{O}_{3} / \mathrm{Pt}\end{array}$ & $\begin{array}{l}\text { Impregnation and evaporation with indium nitrate and } \\
\text { chloroplatinic acid of SBA-15_SnO } \mathrm{Sn}_{2} / \mathrm{In}_{2} \mathrm{O}_{3}(3 / 1)\end{array}$ \\
\hline
\end{tabular}

\section{4. Sensing tests and experimental set-up}

The sensing principle for the detection of hydrogen and propene was the change of the electrical resistance value of a thin solid layer of the above synthesized solids, in the presence of the mentioned gas species, in synthetic air, at temperature values where the catalytic oxidation on the surface leads to noticeable changes in the electronic density of the surface, between 350 $450^{\circ} \mathrm{C}$.

The solid has been deposited by the casting technique from a suspension in ethanol, on a $2 \times 2 \mathrm{~mm}$ piece of substrate. The substrate was obtained by cutting individual finger areas from a disk of $\mathrm{Si} / \mathrm{SiO}_{2}(100 \mathrm{~nm})$ (8 $\mathrm{cm}$ i.d and $0.5 \mathrm{~mm}$ depth), on which a finger structure of $\mathrm{Ti}(5 \mathrm{~nm})$ and $\mathrm{Au}(200 \mathrm{~nm})$ was obtained by sputtering, followed by lift-off technology. The width of the electrodes and the gap distance were of $80 \mu \mathrm{m}$. The $2 \times 2 \mathrm{~mm}$ substrate was glued on a heater to ensure the desired temperature on the substrate (Pt wire in aluminum oxide matrix from Heraeus), connected to a Pt 100 element allowing the continuous temperature measuring and immobilized in a 16-pin holder of about $12 \mathrm{~mm}$ in diameters. Two of the pins were connected to the finger electrode pair and to a multimeter device (TTI 1604), allowing the measurement of the electrical resistance of the solid layer between the finger gaps, working in the range from $1 \mathrm{kOhm}$ to 20 MOhms. The 16-pin holder was inserted in a sealed aluminum cell connected to gas inlet and outlet purge. Details about the experimental setup can be found in our previous papers [32, 33].

The stabilization of the deposited layer was obtained by annealing the sensor in nitrogen atmosphere, for one hour, at $400^{\circ} \mathrm{C}$. The exposure to several hydrogen and propene concentrations in synthetic air was possible by using a gas mixer system, which allowed the desired gas mixture to be precisely prepared and flow through the test cells. The valves opening and shutting were performed by a computer using specific software. 
The overall gas flow through the cells was $100 \mathrm{~mL} \mathrm{~min}^{-1}$. The hydrogen and propene concentrations were 50, 100, 200, 400, 400 ppm in air. The testing temperatures comprised in the range $350-450^{\circ} \mathrm{C}$. The exposure to each concentration of the testing gas lasted 10 minutes and was followed by a 10 minutes exposure to synthetic air, prior to the switch to the next test gas concentration.

\section{Characterization methods}

The structure, the phase identity and the textural properties of the obtained solids were investigated by X-Ray Diffraction (XRD), pure $\mathrm{N}_{2}$ adsorption/desorption by BET method, Scanning Electron Microscopy (SEM) and Transmission Electron Microscopy (TEM) techniques.

The XRD patterns were recorded using a TUR M-62 powder diffractometer system with $\mathrm{CuK} \alpha$ radiation $(\mathrm{K} \alpha=0.1518 \AA, 36 \mathrm{kV}, 20 \mathrm{~mA})$, a voltage of $36 \mathrm{kV}$, a current of $20 \mathrm{~mA}$, and a goniometer speed of $\left.0.5^{\circ} \mathrm{C} / \mathrm{min}\right)$. BET (Brunauer, Emmett and Teller) specific surface areas $\left(\mathrm{S}_{\mathrm{BET}}\right.$ $\left(\mathrm{m}^{2} / \mathrm{g}\right)$ were obtained from the nitrogen adsorption experiments measured at $-196^{\circ} \mathrm{C}$ after degassing the samples below $10^{-3}$ Torr at $200^{\circ} \mathrm{C}$ for $2 \mathrm{~h}$ on NOVA 2200e (Quantachrome Instruments, Boynton Beach, FL, USA). The pore size distribution was determined from the desorption branch of the isotherm using BJH (Barrett-Joyner-Halenda) method. The total pore volume (TPV, $\mathrm{cm}^{3} / \mathrm{g}$ ) was calculated as the amount of nitrogen adsorbed at the relative pressure of ca 0.99 .

The particle morphology was investigated by a LEO 1550 VP field emission scanning electron microscopy (SEM). The TEM investigations were performed using an FEI Tecnai G2TF 20 UT field-emission microscope operated at $200 \mathrm{kV}$.

\section{Results and Discussions}

\section{1. Characterization of the catalytic siliceous materials}

The XRD pattern of the synthesized mesoporous SBA-15 (inset in Figure 1) indicates that the obtained matrix possess a 2D-hexagonal packed mesostructure. The XRD pattern exhibit three diffraction peaks between $0.5-2^{\circ}(2 \theta)$ corresponding to the (100), (110) and (200) reflections, commonly observed for this kind of materials. The SEM image showed the formation of rod-like domains of SBA-15 material. Typical $\mathrm{N}_{2}$ adsorption/desorption isotherm of type IV exhibiting a hysteresis loop of type $\mathrm{H}_{1}$, with parallel adsorption and desorption branches due to the regular array of cylindrical pore characteristic of SBA-15 materials, may be observed (Figure 2). The total surface area, measured using the $\mathrm{N}_{2}$ adsorption/desorption at $-196^{\circ} \mathrm{C}$, was determined to be 862 $\mathrm{m}^{2} / \mathrm{g}$. 

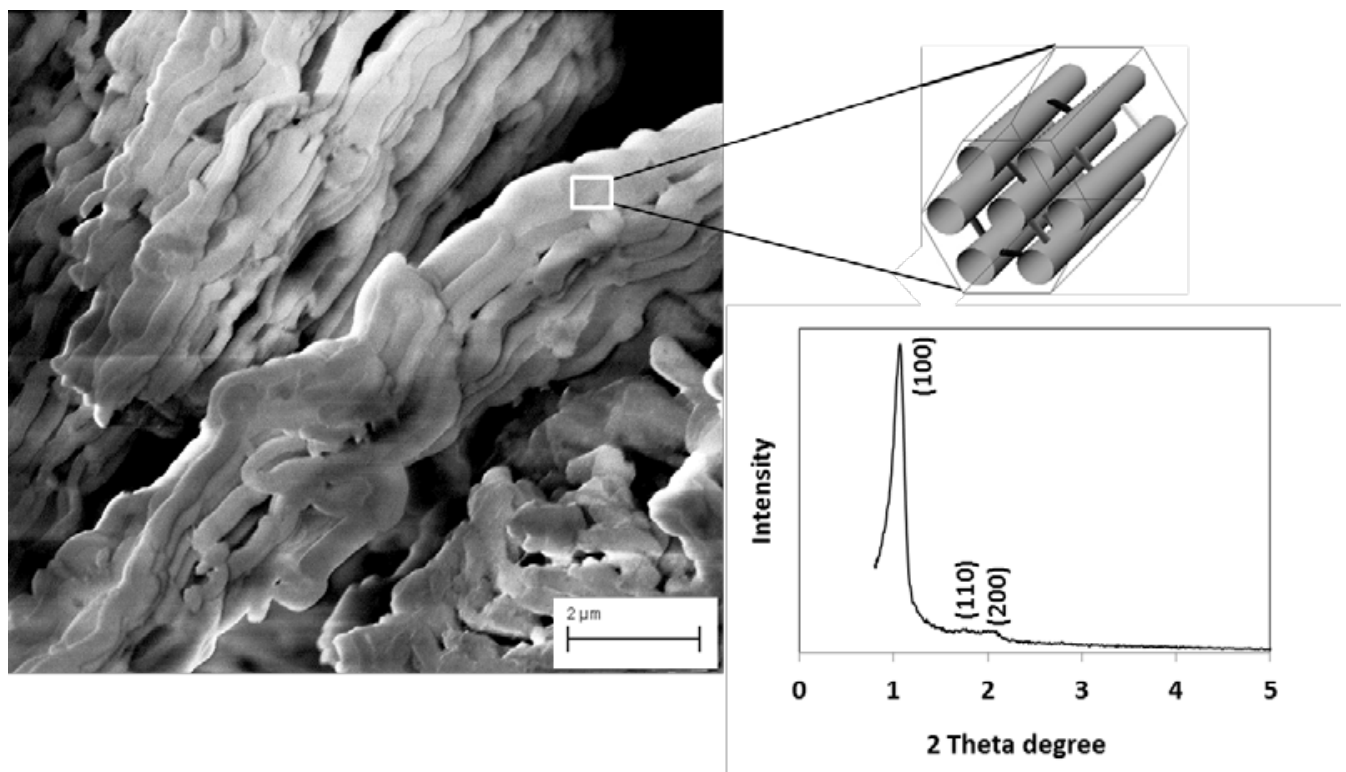

Figure 1. Typical SEM image and XRD pattern of the SBA-15 mesoporous matrix.

Figure 2 displays the nitrogen adsorption/desorption isotherms of SBA-15-type materials before and after metal oxide $\left(\mathrm{SnO}_{2}\right.$ and $\left.\mathrm{In}_{2} \mathrm{O}_{3}\right)$ deposition steps.

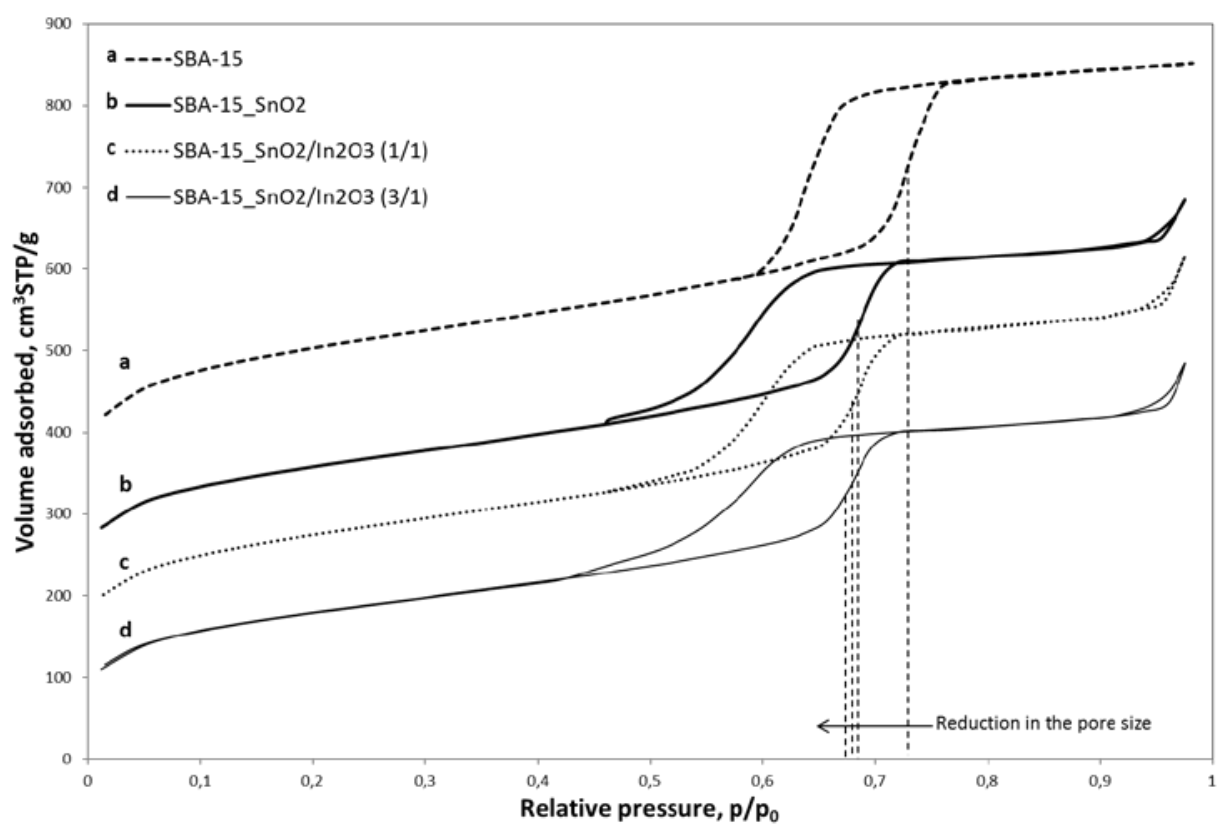

Figure 2. $\mathrm{N}_{2}$ adsorption/desorption isotherms of representative samples. The isotherms are offset by 250 (SBA-15), 100 $\left(\mathrm{SBA}-15 \mathrm{SnO}_{2}\right)$ and 75 (SBA-15_SnO $\mathrm{Sn}_{2} / \mathrm{In}_{2} \mathrm{O}_{3}(3 / 1) \mathrm{cm}^{3} / \mathrm{g}$.

The isotherms of the obtained samples exhibit the characteristic behavior of ordered mesoporous materials showing Type IV isotherms with a well-defined $\mathrm{H}_{1}$ hysteresis loop indicating that the 
mesoporous structure is not disrupted after the metal oxide loading. After the incorporation of the tin oxide into the SBA-15 channels, a decrease of the amount of the adsorbed nitrogen was noticed. As expected, the total BET surface area of the loaded samples decreased as compared to the pristine SBA-15, indicating that some of the metal oxide nanoparticles may be located inside the pores (Table 2). Moreover, a shift of the inflexion point of the desorption step to a smaller relative pressure occurred which, in agreement with previous observations, may indicate the presence of narrowed mesopores causing lower desorption pressure $\mathrm{p} / \mathrm{p}_{0}$ and changes in the shape of the desorption branch of the isotherm. As a consequence, a two steps desorption branch is observed for the metal oxide loaded samples indicating an alteration of the pore shape [34].

Table 2. Textural properties of the catalysts

\begin{tabular}{|c|c|c|c|c|c|}
\hline Sample & $\mathrm{BET}^{\mathrm{a}}\left(\mathrm{m}^{2} / \mathrm{g}\right)$ & $\begin{array}{c}V_{\text {tot }}{ }^{b} \\
\left(\mathrm{~cm}^{3} / \mathrm{g}\right)\end{array}$ & $\mu S^{c}\left(m^{2} / g\right)$ & $\begin{array}{c}\mu V^{d} \\
\left(\mathrm{~cm}^{3} / g\right)\end{array}$ & $\begin{array}{l}D_{\mathrm{BJH}}{ }^{e} \\
(n m)\end{array}$ \\
\hline SBA-15 & 862 & 0.752 & 375 & 0.182 & 7.643 \\
\hline SBA-15_SnO ${ }_{2}$ & 620 & 0.742 & 181 & 0.117 & 6.682 \\
\hline $\mathrm{SBA}-15 \_\mathrm{SnO}_{2} / \mathrm{In}_{2} \mathrm{O}_{3}(1 / 1)$ & 612 & 0.746 & 180 & 0.125 & 6.64 \\
\hline $\mathrm{SBA}-15 \mathrm{SnO}_{2} / \mathrm{In}_{2} \mathrm{O}_{3}(3 / 1)$ & 558 & 0.674 & 145.7 & 0.1003 & 6.63 \\
\hline
\end{tabular}

${ }^{\mathrm{a}} \mathrm{BET}=$ specific surface area; ${ }^{b} \mathrm{~V}_{\text {tot }}=$ total pore volume at $\mathrm{p} / \mathrm{p}_{0}=0.99 ;{ }^{c} \mu \mathrm{S}=$ microporous surface area; ${ }^{d} \mu \mathrm{V}=$ micropore volume; ${ }^{\mathrm{e}} \mathrm{D}_{\mathrm{BJH}}=$ pore diameter, based on the adsorption pore size distribution.

The decrease in the pore diameter also indicates the insertion of the metal oxide nanoparticles inside the silica channels. Moreover, a gradual disappearance of the micropores can also be observed when loading the tin oxide and then the indium oxide on SBA-15. Correlating with the BET analysis, it may be presumed that the decrease of the surface area during tin addition is essentially due to the loss of micropores. In a later stage of the synthesis, when indium is added, depending on the $\mathrm{Sn}^{4+/} \mathrm{In}^{3+}$ ratio, the location of the indium nanoparticles may be tuned. When the initial cationic ratio $\mathrm{Sn}^{4+} \mathrm{In}^{3+}$ is equimolar in the synthesis mixture, no modification of the microporous range is observed. Taking into account that the pore diameter decreases slightly, we may conclude that the indium oxide nanoparticles are located in the silica mesopores. When low amounts of indium are added, e.g. the SBA-15_SnO $\mathrm{Sn}_{2} / \mathrm{In}_{2} \mathrm{O}_{3}(3 / 1)$ sample, the further decrease of the microporous area may be observed, with no major influence on the pore size value, indicating that the indium oxide nanoparticles are located in both micropores and mesopores of the silica material. 

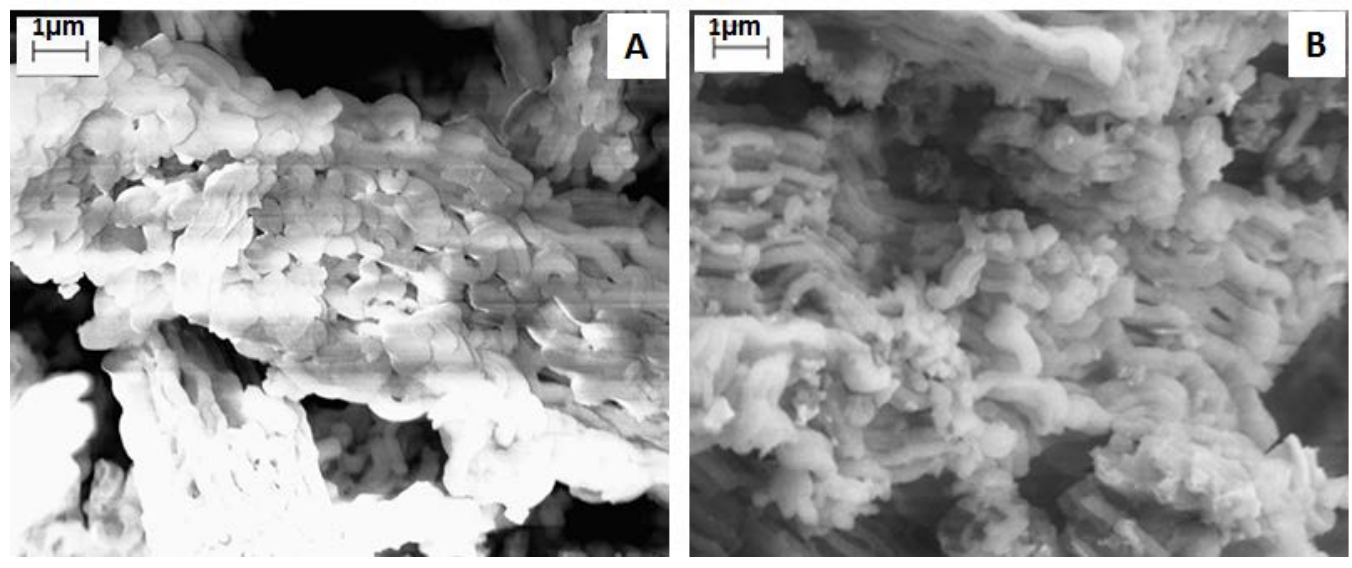

Figure 3. SEM images of (A) SBA-15_SnO ${ }_{2}$ and (B) SBA-15_SnO $\mathrm{Sn}_{2} / \mathrm{In}_{2} \mathrm{O}_{3}(3 / 1)$.

Scanning electron micrographs of the loaded silica samples (Figure 3) show the formation of more numerous, but shorter rod-like units that aggregate into a wheat-like microstructure, when comparing with the parent SBA-15 material (see Figure 1). This feature is more obvious when indium is present into the system (Figure 3B).

Transmission electron micrographs (Figure 4) show the presence of a hexagonal array of uniform channels. Tin oxide nanoparticles appear to form a thin film anchored inside of the channels of the SBA-15 (Figure 4a-c).

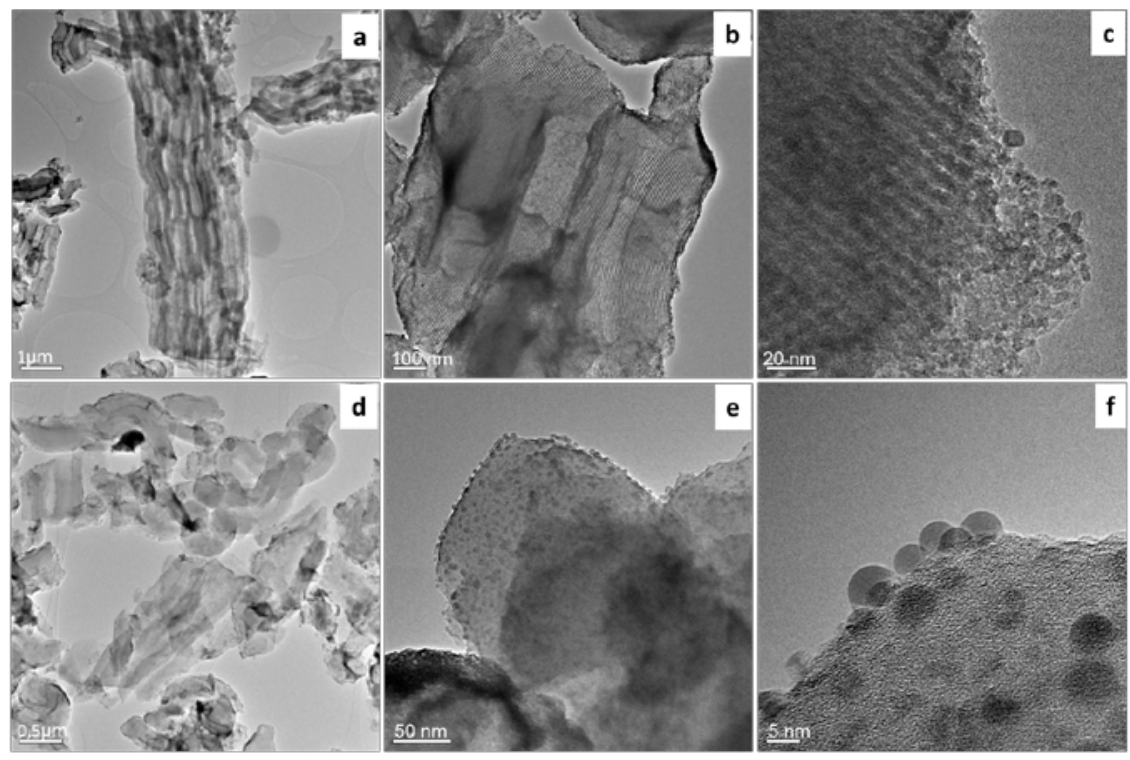

Figure 4. TEM/HR-TEM analysis of the (a), (b), (c) SBA-15_SnO ${ }_{2}$ and (d), (e), (f) $\mathrm{SBA}-15 \mathrm{SnO}_{2} / \ln _{2} \mathrm{O}_{3}(3 / 1)$ samples.

When loading with $\operatorname{In}_{2} \mathrm{O}_{3}$, the TEM image shows that the rod-like units are smaller and randomly aggregated which may be well correlated with the SEM observations. Moreover, the 
$\mathrm{In}_{2} \mathrm{O}_{3}$ nanoparticles are isolated and homogeneously distributed throughout the entire silica framework without agglomeration.

As previously mentioned in the Experimental Section, the $\mathrm{SnO}_{2} / \mathrm{In}_{2} \mathrm{O}_{3}$ loaded SBA-15 samples were further doped with noble metals, such as platinum, based to the fact that the noble metals may be high-effective oxidation catalysts and this ability can be used to enhance the reactions on gas sensor surfaces. The reason for this combination will be further detailed in section 4.2 .

The Pt-doped samples were prepared by impregnation, aiming to obtain homogeneously distributed Pt nanoparticles onto the SBA-15_SnO $\mathrm{Sn}_{2} / \mathrm{In}_{2} \mathrm{O}_{3}$ (1/1) and SBA-15_SnO $\mathrm{S}_{2} / \mathrm{In}_{2} \mathrm{O}_{3}$ (3/1) samples. TEM analysis of the platinum-doped samples (Figure 5) confirmed that the Pt nanoparticles of sizes in the range of 4 to $10 \mathrm{~nm}$ are relatively homogenously distributed in the obtained products. EDX measurements on the dark spots in the HR-TEM images confirmed that these are mostly Pt nanoparticles. The TEM analysis combined with the $\mathrm{N}_{2}$ sorption measurements clearly indicates that the mesoporous structure is not disrupted after the metal loading. 

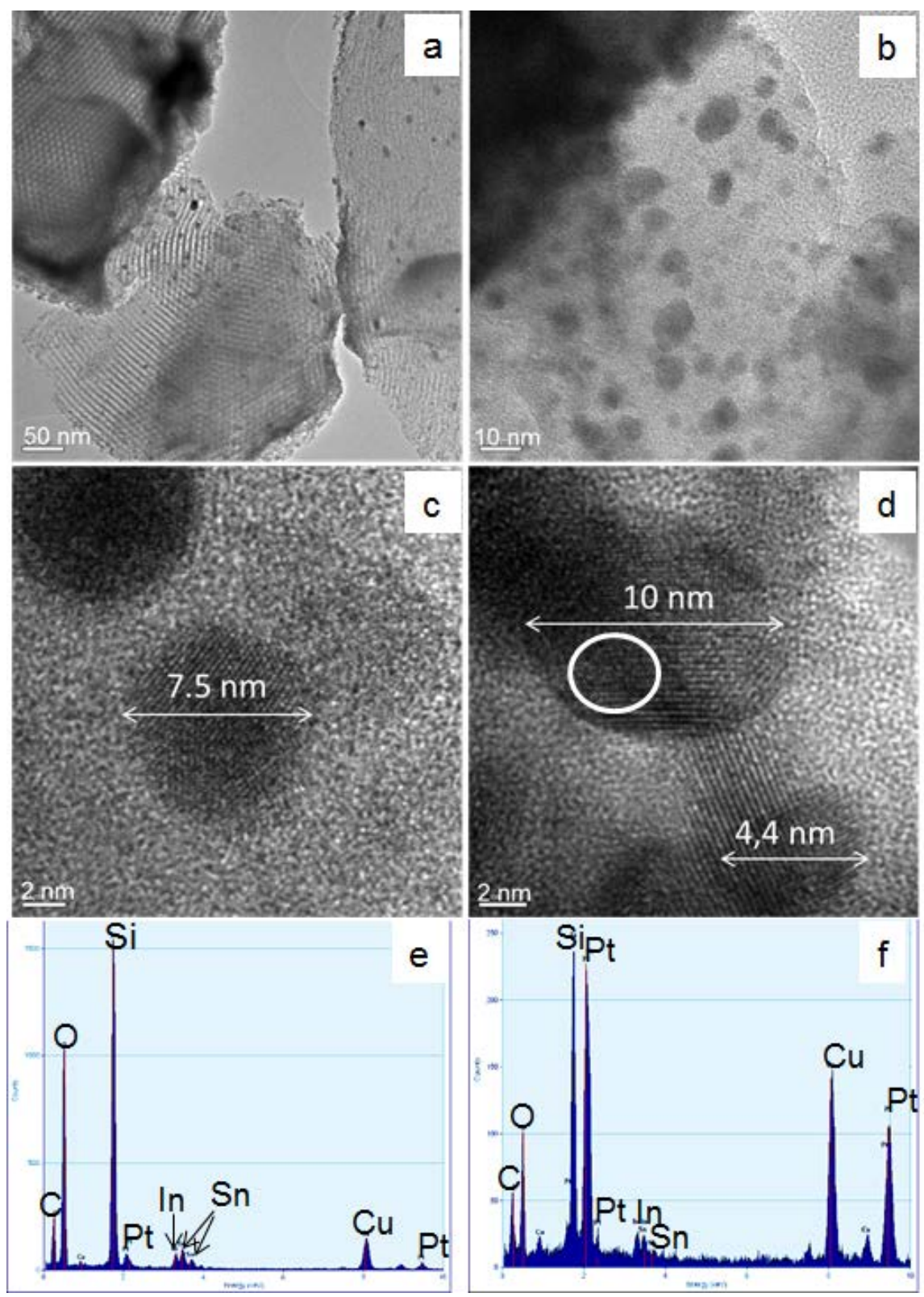

Figure 5. TEM micrographs (a-d) of the $\mathrm{SBA}-15 \mathrm{SnO}_{2} / \mathrm{In}_{2} \mathrm{O}_{3}(3 / 1) \_\mathrm{In}_{2} \mathrm{O}_{3} / \mathrm{Pt}$ sample; the EDX analysis: (e) average measurement on micrograph (a); and (f) measured in the marked spot on micrograph (d).

As expected, the total BET surface area (of $336 \mathrm{~m}^{2} / \mathrm{g}$ ) decreased after the metal loading as compared with the SBA-15_SnO $\mathrm{S}_{2} / \mathrm{In}_{2} \mathrm{O}_{3}$ samples (see Table 2) indicating that some of the metal particles may be located inside the pores. Taking into account the size of the Pt nanoparticles and the pore diameter (of $4.764 \mathrm{~nm}$ ) measured using the $\mathrm{BJH}$ method we may conclude that the $\mathrm{Pt}$ nanoparticles are located both inside the mesopores as well as on the outer surface of the silica walls.

\subsection{Sensor measurements}

The combination between the composition of the active layer - Sn and In oxides and Pt and the porous structure of the mesoporous SBA-15 was chosen in order to beneficiate of the 
presence of these catalytically active species for the reducing gases sensing and the preservation of a accessible outer surface for oxygen and reducting species adsorption.

A challenge in the work was however to obtain sufficient close packing of the doped SBA-15 grains, in order to generate a conductive layer between the particles, as well as good adhesion on the finger structure, if we remember the geometry and the small size of the exposure cell, and the preparative details presented in section 2.4. We could obtain a reasonable stabile layer only for the SBA-15_SnO ${ }_{2} / \mathrm{In}_{2} \mathrm{O}_{3}(3 / 1) \mathrm{In}_{2} \mathrm{O}_{3} / \mathrm{Pt}$ sample. Figure 6 below displays, as an example of sensing properties, the variation of the electrical resistance value of the layer when exposed to 50-400 ppm hydrogen and to 50-400 ppm propene gas in a flow $\left(100 \mathrm{ml} \mathrm{min}^{-1}\right)$ of synthetic air.

The electrical resistance change in reducing gas environments (hydrogen or propene) and the layer responds quite fast to the presence of the gas. The fast response may be accredited to the synergistic effect between the sensor active components. Noisy signals and baseline variation are fairly easy to compensate for in software for the operation of the sensors. Also, further improvements of sensing layers and sensor layout are possible.

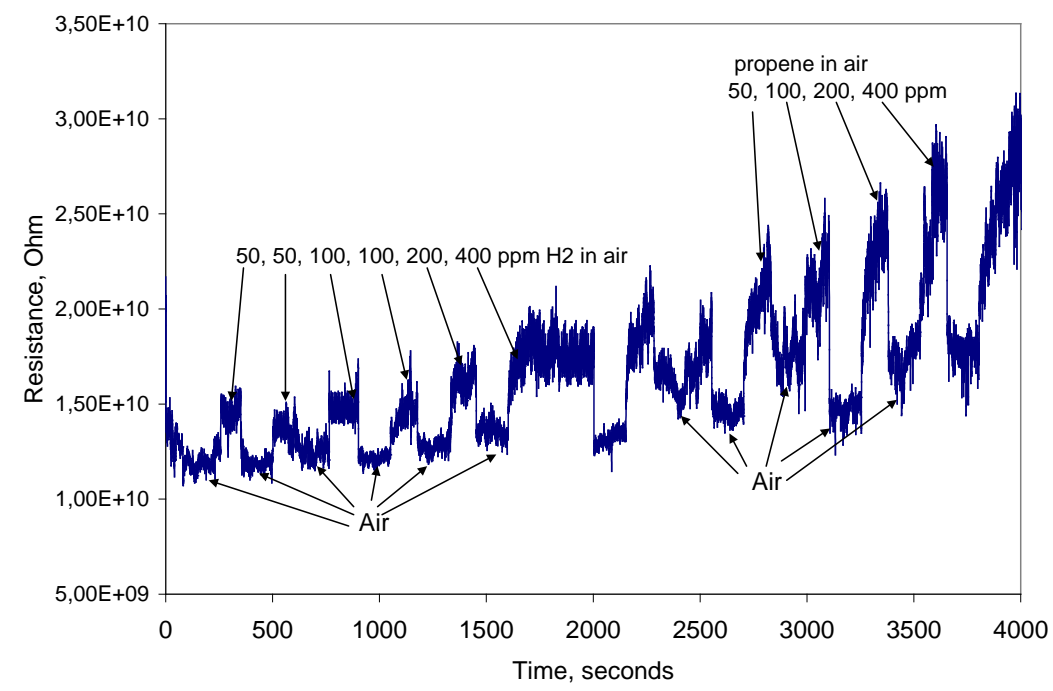

Figure 6. Measurements of sensing properties of the sample SBA-15_SnO ${ }_{2} / \mathrm{In}_{2} \mathrm{O}_{3}(3 / 1) \_\mathrm{In}{ }_{2} \mathrm{O}_{3} / \mathrm{Pt}$, at $450^{\circ} \mathrm{C}$.

The most efficient materials reported for the reducing gas sensing are the noble metals (especially platinum) and some transition metal oxides (especially tin oxide and indium-tin mixed oxide, ITO) [6 and refs. herein]. The sensing mechanism can be explained on the basis of the phenomena occurring at the interface between a semiconductor oxide, a noble metal and a gas phase. A "triple-phase boundary" structure is formed, allowing the oxygen to adsorb as $\mathrm{O}^{\mathrm{n}-}$ ions (n $=0.5,1$ or 2 ) on the basis of electrons extracted from the semiconductive oxide, generating a depletion region on the shell of the material, inducing a thin space charge region [35]. A potential barrier $\mathrm{eV}_{\mathrm{s}}$ appears in this region, whose value can be expressed in function of the total concentration of the $\mathrm{O}^{\mathrm{n}-}$ anions [35]: 


$$
\mathrm{eV}_{\mathrm{s}}=\frac{\mathrm{e}^{2} \mathrm{~N}_{\mathrm{t}}{ }^{2}}{2 \varepsilon \varepsilon_{0} \mathrm{~N}_{\mathrm{d}}},
$$

where e is the electron charge, $\mathrm{N}_{\mathrm{t}}=\left[\mathrm{O}^{2-}\right]+\left[\mathrm{O}^{-}\right]+\left[\mathrm{O}^{2-}\right], \varepsilon \varepsilon_{0}$ is the semiconductor permittivity and $\mathrm{N}_{\mathrm{d}}$ is the bulk density of the donors. The dependence of the conductance of the layer $\mathrm{G}\left(\mathrm{R}^{-1}\right.$, $\mathrm{R}$ being the electrical resistance) on temperature can be expressed as an exponential equation:

$\mathrm{G}=\mathrm{G}_{0} \exp \left(-\mathrm{eV}_{\mathrm{s}} / \mathrm{kT}\right)$,

where $G_{0}$ is a factor including the bulk conductance of the grain layer and their geometric/shape effects and $\mathrm{k}$ is the Boltzmann constant.

The hydrocarbon adsorption on the semiconductive oxide surface is apparently facilitated by the presence of weak Lewis acid-base pairs [36], which activates the C-H bond, leading to the formation of hydrocarbon radical species, which react easier with the adsorbed oxygen from the surface.

Moreover, a synergy between the effect of the semiconductive oxides $\left(\mathrm{SnO}_{2}\right.$ and $\left.\operatorname{In}_{2} \mathrm{O}_{3}\right)$ and the Pt sites must also be mentioned. The Pt sites are well-known for their strong ability to break the $\mathrm{H}-\mathrm{H}$ or $\mathrm{C}-\mathrm{H}$ bonds, due to the capacity to bond the hydrogen atoms [29, 37, 38]. However, the pure platinum layers ("porous platinum”) have a strong tendency to deactivate [29], mainly due to sintering of the layer at high temperatures, resulting in the diminishing of the available surface area for the dissociate hydrogen atoms bonding.

The reaction of the oxygen species with the reducing gas species will decrease and even reverse the band bending, resulting in an increased conductivity. $\mathrm{O}^{-}$is believed to be dominant in the operating temperature range of $300-500^{\circ} \mathrm{C}$, in which most semiconductor gas sensors are operated [38]. Moreover, SBA-15 is well known as a good adsorbent for gases [39], therefore the SBA-15 based composite material would be able to adsorb more oxygen or hydrogen and promote the reaction between the reducing species and the surface adsorbed oxygen, hence increasing the amount of released electrons and increasing the sensitivity of the composite sensor.

Another possible reason for the obtained enhanced sensitivity of the obtained composite material could be attributed to the reduced size of the semiconductor nanoparticles which were synthesized in the constricted space of the SBA-15 nanochannels, since the reduction of the crystal size can cause an important improvement of gas sensitivity [40, 41].

It is interesting to note that propene is generating a much higher signal than hydrogen and the concentration plays a more important role on the signal magnitude than in the case of hydrogen. This behavior could be explained by the more numerous transferred electrons during the burn-off of the adsorbed molecule of propene, than in the case of hydrogen. It is a surprising result, since usually hydrogen give rise to higher sensitivity, than the presence of bulkier and more complex molecules. It is in our opinion due to the internal pore structure of the material, allowing a better adsorption of propene than hydrogen, the latter being adsorbed with priority on Pt sites.

The noisy shape of the curves indicates eventually weak electrical contact to the finger electrodes but more likely, that the contact between the particles in the thin sensing layer is too poor and suggests that the intrinsic properties of the synthesized materials are promising for their 
use as sensors, while extra work needs to be performed to improve the continuous nature of the layer and will be approached in a future study.

\section{Conclusions}

SBA-15-based materials were obtained by the wet impregnation of tin, indium and platinum in various combinations on a parent sample having a surface specific area of $862 \mathrm{~m}^{2} \mathrm{~g}^{-1}$. The structural characterization techniques revealed that the hexagonal structure is preserved during the impregnation procedures. The location of the oxide phases could be manipulated using different cationic ratios in the initial synthesis mixtures. The location of the oxide nanoparticles partly inside SBA-15 mesopores was obtained using the $\mathrm{N}_{2}$ sorption technique in combination with TEM observations. The tin oxide nanoparticles formed mostly a thin film anchored inside the silica channels, while the indium oxide nanoparticles were homogeneously distributed throughout the entire silica framework. In order to enhance the reactions on the gas sensor surface, platinum loaded samples were obtained using an impregnation method. The procedure resulted in homogeneously distributed Pt nanoparticles onto the siliceous materials. The obtained catalytic material was sensitive to both hydrogen and propene, and the results show a better sensitivity to different concentrations of propene than to hydrogen.

\section{Acknowledgements}

This work was partly covered by the financial support of MNT Era Net project no. 09044 SootSens II, MNT 7-028/2010 granted by CNMP - Romania. E. M. Seftel greatly acknowledges the Fund for Scientific Research - Flanders (FWO - Vlaanderen) for financial support. Special thanks to dr. Jose Manuel Cordoba for performing the TEM analysis.

\section{References}

1. J. Tu, N. Li, X. Lai, Y. Chi, Y. Zhang, W. Wang, X. Li, J. Li, S. Qiu, Applied Surface Science 256, 5051 (2010).

2. V. E. Bochenkov, G.B. Sergeev, Advances in Colloid and Interface Science 116, 245 (2005).

3. X. Q. Wang, M. F. Zhang, J. Y. Liu, T. Luo, Y. T. Qian, Sens. Actuators B 137103 (2009).

4. C. Wang, L. Yin, L. Zhang, D. Xiang, R. Gao, Sensors, 102088 (2010) .

5. S. Baset, H. Akbari, H. Zeynali, M. Shafie, Digest J. Nanomat. Biostruct. 6709 (2011).

6. D. Lutic, A. Lloyd-Spetz, M. Sanati, in Synthesis, properties and applications of oxide nanomaterials, ed. by J. A. Rodriguez, M. Fernandez-Garcia, (Wiley Interscience, 2007), p. 410.

7. S. K. Lim, S.-H. Hwang, D. Chang, S. Kim, Sensors and Actuators B: Chemical 14928 (2010)

8. J. Yang, K. Hidajat, S. Kawi, Materials Letters 62, 1441 (2008).

9. J. S. Han, T. Bredow, D. E. Davey, A. B. Yu, D. E. Mulcahy, Sens. Actuators B 7517 (2001) 
10. S. Seal, S. Shukla, JOM Journal of the Minerals, Metals and Materials Society 5435 (2002).

11. J. K. Choi, I.S. Hwang, S. J. Kim, J.S. Park, S.S. Park, U. Jeong, Y.C. Kang, J. H. Lee, Sens. Actuat. B 150, 191 (2010).

12. C. W. Na, H. S. Woo, I. D. Kim, J. H. Lee, Chem. Commun. 47, 5148 (2011).

13. S. Aygun, D. Cann, Sens. Actuat. B 106, 837 (2005).

14. L. A. Patil, D. R. Patil, Sens. Actuat. B 120, 316 (2006).

15. J. Herran, G. G. Mandayo, E. Castano, Sens. Actuat. B 127, 370 (2007).

16. M. C. Carotta, V. Guidi, G. Martinelli, M. Nagliati, D. Puzzovio, D. Vecchi, Sens. Act. B: Chemical 130(1), 497 (2008).

17. G. M. Kale, Adv. Powder Technol. 20, 426 (2009).

18. X. Song, D. Zhang, M. Fan, Applied Surface Science 255, 7343 (2009).

19. T. Kyotani, L.-F. Tsai, A. Tomita, Chem. Commun. 701 (1997).

20. D. Routkevitch, T. Bigion, M. Moskovits, J.M. Xu, J. Phys. Chem. 10014037 (1996).

21. Y. Bai, H. Yang, W. Yang, Y. Li, C. Sun, Sens. Actuators B, 124 (1), 179 (2007).

22. H. H. P. Yiu, P. A. Wright, N. P. Botting, J. Mol. Catal. B, 15(1-3) 81 (2001).

23. R. Ryoo, C. H. Ko, M. Kruk, V. Antochshuk, M. Jaroniec, J. Phys. Chem. B, 104(48), 11465 (2000).

24. M. Impéror-Clerc, P. Davidson, A. Davidson, J. Am. Chem. Soc. 122(48) 11925 (2000).

25. K. Flodström, C. V. Teixeira, H. Amenitsch, V. Alfredsson, M. Lindén, Langmuir 20(12), 4885 (2004).

26. Y. Shimizu, T. Hyodo, M. Egashira, J. Eur. Ceram. Soc. 24, 1389 (2004).

27. G. Satishkumar, L. Titelman, M.V. Landau J. Solid State Chem. 182 (10), 2822 (2009).

28. W. Göpel, Sensors and Actuators A 56, 83 (1996).

29. H. Wingbrant, A. Lloyd Spetz, , Sensor Lett. 137 (2003).

30. D. Zhao, Q. Huo, J. Feng, B. F. Chmelka, G. D. Stucky, J. Am. Chem. Soc. 120(14), 2317 (1998).

31. X. Zhang, W. Wu, T. Tian, Y. Man, J. Wang, Mat. Res. Bull., 431016 (2008).

32. D. Lutic, J. Pagels, R. Bjorklund, P. Josza, J. H. Visser, A.W. Grant, M. L. Johansson, J. Paaso, P.-E. Fagerman, M. Sanati, A. Lloyd Spetz, Journal of Sensors, Article ID 421072, doi:10.1155/2010/421072 (2010).

33. D. Lutic, M. Strand, A. Lloyd-Spetz, K. Buchholt, E. Ieva, P.-O. Kall, M. Sanati, Topics in Catalysis 45(1-4), 105 (2007).

34. V. Meynen, P. Cool, E.F. Vansant, Microp. Mesop. Mat. 104, 26 (2007).

35. A. Tiburcio-Silver, A. Sanchez-Juarez, Mat. Sci. Eng. B 110, 268 (2004).

36. T. Toya, J. Res. Inst. Catal., 236 (1962).

37. K. Kinoshita, J. Lundquist, P. Stonehart J. Catal. 31(3) 325 (1973).

38. E. Van Bavel, V. Meynen, P. Cool, K. Lebeau, E. F. Vansant, Langmuir 21 (6) 2447 (2005).

39. J. Yang, K. Hidajat, S. Kawi, Materials Letters 62, 1441 (2008).

40. N. Yamazoe, Sensors and Actuators B 5, 7 (1991).

41. G. Korotcenkov, B.K. Cho Progr. Cryst. Growth Charact., 58167 (2012). 